\title{
Improvement of Impact Strength of Polylactide Blends with a Thermoplastic Elastomer Compatibilized with Biobased Maleinized Linseed Oil for Applications in Rigid Packaging
}

\author{
Ramon Tejada-Oliveros, Rafael Balart * ${ }^{\mathbb{D}}$, Juan Ivorra-Martinez $\mathbb{D}^{\mathbb{D}}$, Jaume Gomez-Caturla, Nestor Montanes \\ and Luis Quiles-Carrillo *(1)
}

check for updates

Citation: Tejada-Oliveros, R.;

Balart, R.; Ivorra-Martinez, J.;

Gomez-Caturla, J.; Montanes, N.; Quiles-Carrillo, L. Improvement of Impact Strength of Polylactide Blends with a Thermoplastic Elastomer Compatibilized with Biobased

Maleinized Linseed Oil for Applications in Rigid Packaging. Molecules 2021, 26, 240. https:// doi.org/10.3390/molecules26010240

Academic Editor: Stefano Fiori Received: 17 December 2020 Accepted: 1 January 2021 Published: 5 January 2021

Publisher's Note: MDPI stays neutral with regard to jurisdictional clai$\mathrm{ms}$ in published maps and institutional affiliations.

Copyright: (C) 2021 by the authors. Licensee MDPI, Basel, Switzerland. This article is an open access article distributed under the terms and conditions of the Creative Commons Attribution (CC BY) license (https:// creativecommons.org/licenses/by/ $4.0 /)$.
Technological Institute of Materials (ITM), Universitat Politècnica de València (UPV), Plaza Ferrándiz y Carbonell 1, 03801 Alcoy, Spain; rateol@epsa.upv.es (R.T.-O.); juaivmar@doctor.upv.es (J.I.-M.); jaugoca@epsa.upv.es (J.G.-C.); nesmonmu@upvnet.upv.es (N.M.)

* Correspondence: rbalart@mcm.upv.es (R.B.); luiquic1@epsa.upv.es (L.Q.-C.); Tel.: +34-966-528-433 (L.Q.-C.)

Abstract: This research work reports the potential of maleinized linseed oil (MLO) as biobased compatibilizer in polylactide (PLA) and a thermoplastic elastomer, namely, polystyrene- $b$-(ethyleneran-butylene)- $b$-styrene (SEBS) blends (PLA/SEBS), with improved impact strength for the packaging industry. The effects of MLO are compared with a conventional polystyrene- $b$-poly(ethylene-ranbutylene)- $b$-polystyrene-graft-maleic anhydride terpolymer (SEBS- $g$-MA) since it is widely used in these blends. Uncompatibilized and compatibilized PLA/SEBS blends can be manufactured by extrusion and then shaped into standard samples for further characterization by mechanical, thermal, morphological, dynamical-mechanical, wetting and colour standard tests. The obtained results indicate that the uncompatibilized PLA/SEBS blend containing $20 \mathrm{wt}$ \% SEBS gives improved toughness $\left(4.8 \mathrm{~kJ} / \mathrm{m}^{2}\right)$ compared to neat PLA $\left(1.3 \mathrm{~kJ} / \mathrm{m}^{2}\right)$. Nevertheless, the same blend compatibilized with MLO leads to an increase in impact strength up to $6.1 \mathrm{~kJ} / \mathrm{m}^{2}$, thus giving evidence of the potential of MLO to compete with other petroleum-derived compatibilizers to obtain tough PLA formulations. MLO also provides increased ductile properties, since neat PLA is a brittle polymer with an elongation at break of 7.4\%, while its blend with $20 \mathrm{wt} . \%$ SEBS and MLO as compatibilizer offers an elongation at break of $50.2 \%$, much higher than that provided by typical SEBS- $g$-MA compatibilizer (10.1\%). MLO provides a slight decrease (about $3{ }^{\circ} \mathrm{C}$ lower) in the glass transition temperature $\left(T_{g}\right)$ of the PLA-rich phase, thus showing some plasticization effects. Although MLO addition leads to some yellowing due to its intrinsic yellow colour, this can contribute to serving as a UV light barrier with interesting applications in the packaging industry. Therefore, MLO represents a cost-effective and sustainable solution to the use of conventional petroleum-derived compatibilizers.

Keywords: polylactide; thermoplastic elastomer; impact strength; rigid packaging; mechanical properties

\section{Introduction}

In the last decade, a growing social concern about the environment has arisen. This situation is specifically pronounced in the plastics industry due to the huge waste generation, the use of fossil nonrenewable sources and the increasing need to reduce carbon footprint. Currently, polymers and plastics can be found anywhere around us with the subsequent increase in year-by-year production [1,2]. Today, the worldwide plastics production is around $300 \mathrm{Mt}$ per year, and, as most the of the plastics are not biodegradable, they generate a huge amount of plastic waste [3]. This new social awareness is turning the plastics industry towards more environmentally friendly polymeric materials. This transition is focused on two moments related to the life cycle of plastics, i.e., at the origin (natural versus fossil sources) or at the end (potential biodegradation or compost disintegration) $[4,5]$. In particular, a great rise has been observed in the packaging industry, in which the problem has increased over the years due to massive employment of single-use plastics [6]. 
To overcome this situation, industry and researchers have been particularly interested in the development of new polymer materials from renewable resources and/or potentially biodegradable (actually, disintegrable in compost soil with specific composition) [7]. For this reason, materials such as aliphatic polyesters, e.g., poly(lactide) (PLA), poly(glycolic acid) (PGA), and others, e.g., poly(hydroxyalkanoates) (PHA) are becoming very popular. These polymers can be obtained from natural resources or by bacterial fermentation, thus leading to high efficiency materials from an environmental point of view [8-11].

In this sense, PLA is among the most promising biopolymers. PLA can be obtained from starch-rich renewable resources and is increasingly used in the packaging industry, due to its great balance of mechanical, thermal and barrier properties, along with a costcompetitive price and easy processing by conventional techniques [12]. This is why PLA is currently leading the emerging bioplastics market and can be found in a wide range of specialized sectors, such as medical, pharmaceutics and bioengineering, since it is biocompatible and resorbable [13,14]; automotive industry [15-17], additive manufacturing and 3d printing $[18,19]$; or packaging $[20,21]$. However, PLA is intrinsically very fragile and brittle, and this can represent an important drawback for applications that require somewhat toughness such as 3D-printed parts and rigid packaging [22,23].

To solve (or at least, to minimize) this problem, important research has been carried out in recent years focusing on different approaches to overcome this major drawback for most industrial uses. Many works are focused on the use of plasticizers such as oligomers of lactic acid (OLAs), with exceptional results on toughness [24,25], poly(ethylene glycol) (PEG) [26] or triethyl citrate (TEC) [27], with the main aim of increasing the elongation at break of PLA and its overall ductile behaviour. Nevertheless, the use of plasticizers is usually associated with a decrease in the glass transition temperature $\left(T_{g}\right)$, and subsequently, mechanical resistant properties are lower. Another interesting approach is copolymerization with flexible monomers, for example, poly(lactide)-g-poly(butylene succinate-co-adipate) [28]. Although a remarkable improvement in toughness can be obtained through copolymerization, this is not a cost-effective solution.

Among the different strategies, the use of binary/ternary blends represents a costeffective solution to tailor the target properties and to reduce the final cost of biopolymers. To overcome the intrinsic fragility of polymers, these can be blended with flexible polymers that act as impact modifiers. Often, these blends consist of partially miscible or even immiscible flexible polymers that are finely dispersed into the brittle polymer matrix. In these partially or fully immiscible blends, the use of compatibilizers to enhance the interactions between them is encouraged [29]. Poly(styrene)- $b$-(ethylene-ran-butylene)- $b$ (styrene) (SEBS) is a thermoplastic elastomer (TPE) that behaves like a rubber and could act as an impact modifier in PLA-based formulations for improved toughness. In general, TPEs offer an excellent balance between processability (thermoplastic) and rubber-like properties, and are increasingly used [30]. SEBS is obtained by hydrogenation of unsaturations contained in polystyrene-butadiene-styrene (SBS). The absence of unsaturations in the hydrogenated structure provides excellent thermal and UV resistance [31], which is a key factor in the food packaging industry. In addition, due to its wide range of elasticity and hardness values (depending on the ethylene-butylene segments) and easy processing at relatively low temperatures, it is used in a wide range of sectors such as adhesives, cable coatings, films, toys, household appliances and, increasingly, in the medical and automotive sectors [32,33]. SEBS has been reported to provide improved impact strength and overall ductility in poly(propylene)/poly(styrene) blends as well as in polyamide-based formulations [34-36].

Nevertheless, as above-mentioned, many polymer blends are composed of partially miscible or fully immiscible polymers, which leads to a poor interfacial adhesion. Consequently, the final performance of these blends is lower than expected [37,38]. In these cases, the use of a compatibilizer agent is almost mandatory to provide a bridge or coupling effect between the two polymers in the blend [39]. To improve the miscibility between polymers, 
there are two main techniques: ex situ (non-reactive) or in situ (reactive) compatibilization. The first technique refers to the use of a third component, usually a grafted or block copolymer obtained under a careful design and synthesis to be largely miscible with both components of the blend. These compatibilizers preferentially are located at the interface between the immiscible (or partially miscible) polymers allowing polymer-polymer interactions which can increase interfacial adhesion and morphological stability, thus improving the overall performance of the blend [40]. Some of these compatibilizers are obtained by grafting a highly reactive group, such as maleic anhydride, carboxylic acid, oxirane ring and acrylate group, into the main polymer backbone to provide dual functionality. Thus, it is possible to find SEBS- $g$-MA which is a SEBS polymer (non-polar) grafted with maleic anhydride (with high polarity). SEBS- $g$-MA is widely used as compatibilizer in polar/non-polar systems due to its dual functionality [41]. A remarkable increase in the impact strength, tensile strength and elongation at break of recycled polyacrylonitrilebutadiene-styrene (rABS) by blending with SEBS and using SEBS- $g$-MA as compatibilizer has been reported $[42,43]$.

The second technique, the so-called reactive extrusion (REX), is a simpler and more cost-effective technique that uses polymers, oligomers and additives that react during the extrusion process with certain functional groups [44]. Usually, REX extrusion requires the use of initiators to introduce a variety of functional groups into biopolymer chains [45]. In recent years, vegetable oils have attracted high interest in the polymer industry as they can be used as renewable sources for polymer synthesis and additives for industrial formulations. Modified vegetable oils have been used as plasticizers, compatibilizers, stabilizers, crosslinkers, among others. It is worth noting the increasing use of epoxidized vegetable oils (EVOS) such as epoxidized soybean oil (ESBO) $[46,47]$, epoxidized linseed oil (ELO) [48,49] or epoxidized palm oil (EPO) [50]. All these EVO have been successfully used in polymer blends and composites with a plasticization/compatibilization main effect, due to the reactivity of the oxirane group. In addition to epoxidized vegetable oils, maleinization is another interesting chemical modification of vegetable oils. Maleinized linseed oil (MLO) has been used as compatibilizer in wood plastic composites with poly(butylene succinate) (PBS) matrix and almond shell flour [51]. The exceptional properties MLO can provide to PLA-based composites with regard to its impact strength and overall ductile properties have been reported [52].

The main objective of this work is to improve the impact strength of PLA by blending with SEBS to increase and broaden the use of PLA in the packaging industry. The novelty of this work is the use of a biobased maleinized linseed oil (MLO) as cost-effective compatibilizer to overcome the immiscibility between both polymers, due to its dual functionality which can interact with both PLA and SEBS. A conventional petroleum-derived SEBS- $g$-MA compatibilizer is used as control compatibilizer since it is widely used in these blends. The effect of these compatibilizing systems on the mechanical, morphological, thermal, thermomechanical, visual aspect and wetting characteristics of PLA/SEBS is studied, and the potential of a biobased compatibilizer derived from linseed oil (MLO) as a potential substitute of other petroleum-derived compatibilizers to provide improved toughness is assessed.

\section{Results and Discussion}

\subsection{Mechanical Properties}

The results of the mechanical characterization of PLA/SEBS blends with different compatibilizing systems are shown in Table 1 . These results reveal the effectiveness of each compatibilizing systems used to obtain improved toughness PLA formulations. 
Table 1. Summary of mechanical properties of the injection-molded samples of uncompatibilized and compatibilized PLA/SEBS blends. Tensile modulus $(E)$, maximum tensile strength $\left(\sigma_{\max }\right)$ and elongation at break $\left(\% \varepsilon_{b}\right)$, Shore D hardness and impact (Charpy) strength.

\begin{tabular}{|c|c|c|c|c|c|}
\hline Code & $\mathrm{E}(\mathrm{MPa})$ & $\sigma_{\max }(\mathrm{MPa})$ & $\varepsilon_{b}(\%)$ & Shore D Hardness & Impact Strength $\left(\mathrm{kJ} / \mathrm{m}^{2}\right)$ \\
\hline PLA & $2977 \pm 27^{a}$ & $35.8 \pm 2.6^{\mathrm{a}}$ & $7.4 \pm 0.8^{\mathrm{a}}$ & $80.0 \pm 0.8^{a}$ & $1.3 \pm 0.1^{\mathrm{a}}$ \\
\hline PLA/SEBS & $1419 \pm 32^{b}$ & $6.3 \pm 0.7^{b}$ & $7.8 \pm 1.0^{\mathrm{a}}$ & $63.0 \pm 0.7^{b}$ & $4.8 \pm 0.5^{b}$ \\
\hline PLA/SEBS/SEBS- $g$-MA & $802 \pm 39^{c}$ & $4.7 \pm 0.6^{\mathrm{c}}$ & $10.1 \pm 1.1^{b}$ & $51.6 \pm 1.1^{\mathrm{c}}$ & $4.0 \pm 0.1^{b}$ \\
\hline PLA/SEBS/MLO & $1275 \pm 61^{b}$ & $5.2 \pm 0.6^{\mathrm{c}}$ & $50.2 \pm 4.3^{\mathrm{c}}$ & $58.8 \pm 0.4^{b}$ & $6.1 \pm 0.6^{c}$ \\
\hline PLA/SEBS/SEBS- $g$-MA/MLO & $897 \pm 83^{c}$ & $5.9 \pm 0.6^{\mathrm{b}}$ & $23.0 \pm 3.0^{\mathrm{d}}$ & $58.2 \pm 0.8^{b}$ & $3.5 \pm 0.1^{\mathrm{b}}$ \\
\hline
\end{tabular}

${ }^{a-d}$ Different letters in the same column indicate a significant difference among the samples $(p<0.05)$.

As can be seen, the tensile modulus (E) and the tensile strength $\left(\sigma_{\max }\right)$ of neat PLA are 2977 and $35.8 \mathrm{MPa}$, respectively. These mechanical properties are interesting and higher than most commodities; nevertheless, the elongation at break of PLA is only $7.4 \%$ which is representative for very low ductile properties, thus leading to a stiff and brittle polymer. These characteristic values of PLA have been reported by other authors [53]. As expected, the addition of SEBS (20 wt.\%) leads to a decrease in both tensile modulus and tensile strength. It strikes the low tensile strength values, typical of a rubber-like material, but this can be attributed to the extremely low hardness SEBS grade (5 Shore A). Nevertheless, the elongation at break was slightly improved without any compatibilizer system or, what is more important, it was not dramatically reduced as it happens in immiscible blends. These poor mechanical properties are directly related to the blend structure. It has been reported that PLA and SEBS are not miscible and, consequently, the overall properties of the uncompatibilized PLA/SEBS blend are poor [54]. With the use of different compatibilizing systems on the base PLA/SEBS blend, some interesting findings are revealed. The addition of SEBS- $g$-MA contributes to some compatibilization since the elongation at break is improved, while the stiffness is reduced. This is related to improved PLA/SEBS interactions since the SEBS chains in SEBS- $g$-MA are compatible with SEBS, while the grafted maleic anhydride can react with terminal hydroxyl groups in PLA, thus leading to a coupling effect [55]. MLO-compatibilized PLA/SEBS blend offers interesting properties. The material has a flexible behaviour with a tensile modulus of $1275 \mathrm{MPa}$ and a tensile strength typical of an elastomer (5.2 MPa). It is worth noting the positive effect of MLO on elongation at break of PLA/SEBS blend with a value of $50 \%$. Modified vegetable oils can provide several properties to polyester-type polymers such as chain extension, branching, crosslinking and plasticization. Depending on the main mechanism, different mechanical performance can be obtained. It has been reported that acrylated epoxidized soybean oil (AESBO) shows a remarkable rise in ductile properties of PLA [46]. The compatibilization system that comprises a mixture of SEBS- $g$-MA and MLO gives intermediate values between those offered by the individual compatibilizers. The compatibilizing effects of both maleinized compounds can be schematically seen in Figure 1.

Table 1 also gathers the results corresponding to the impact strength. PLA is a brittle polymer with an impact strength of $1.3 \mathrm{~kJ} / \mathrm{m}^{2}$. The uncompatibilized PLA/SEBS blend shows a remarkable increase in impact strength up to values of $4.8 \mathrm{~kJ} / \mathrm{m}^{2}$ which represents a percentage increase of $269 \%$, compared to neat PLA. Lima et al. [54] reported similar values for PLA containing 20\% SEBS. This noticeable increase in the impact strength could be attributed to the flexible ethylene-butylene blocks contained in SEBS, which act as impact absorbers due to their rubber-like behaviour. Other studies have revealed the positive effect of SEBS on the impact strength of poly(propylene)-short glass fiber composites. Reactive extrusion with maleic anhydride allowed obtaining an increase of $300 \%$ higher than the uncompatibilized composites [56]. Regarding the effect of SEBS-g-MA on impact strength, it is worth noting a slight decrease in impact strength with regard to uncompatibilized PLA/SEBS blend. The MLO-based compatibilizer system seems to give the best toughness improvement with an impact strength of $6.1 \mathrm{~kJ} / \mathrm{m}^{2}$ (almost five 
times higher than neat PLA), while no synergistic effect can be observed for the binary (SEBS-g-MA + MLO) compatibilizing system. By considering both tensile and impact properties, MLO seems to give the best-balanced mechanical properties. The excellent compatibilization/plasticization effect of MLO on binary PLA-thermoplastic starch (TPS) blends has been reported [57].

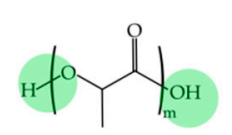

polylactide - (PLA)

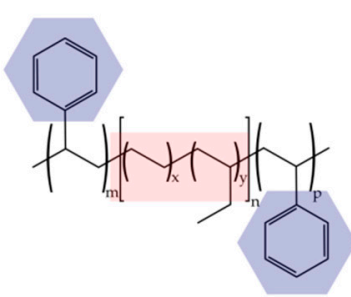

polystyrene-block-(ethylene-ran-butylene)-block-styrene - (SEBS)

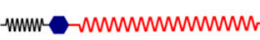

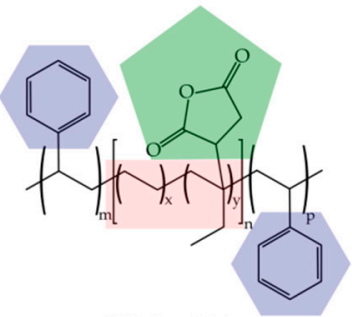

SEBS- $g$-MA

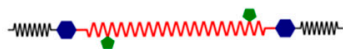

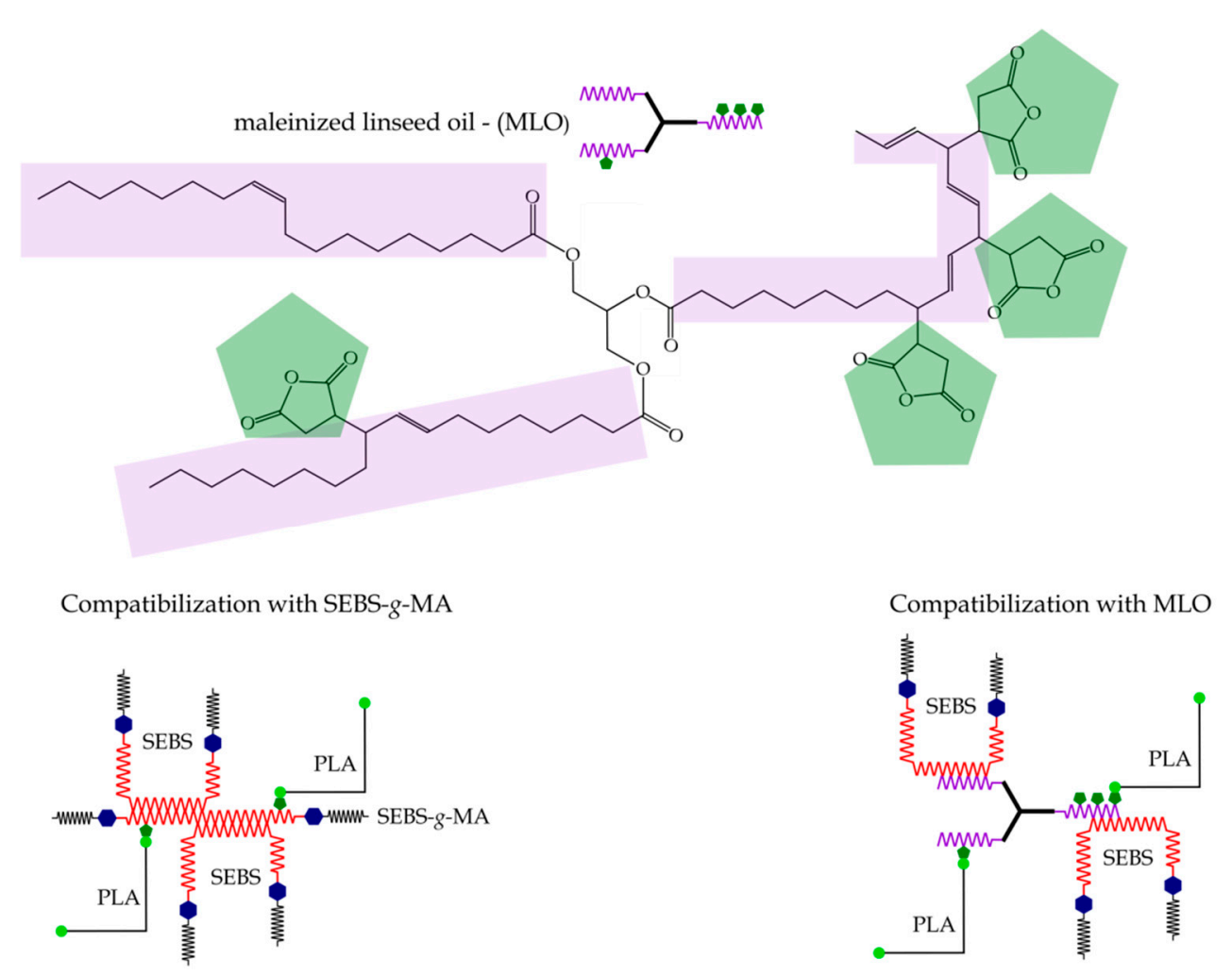

Figure 1. Proposed interaction mechanism between the PLA/SEBS blend and the different compatibilizing agents.

Regarding Shore D hardness, it is possible to observe the same tendency to that observed for the tensile modulus. Neat PLA has a Shore D hardness values of 80 , while its blend with $20 \mathrm{wt} . \%$ SEBS shows a Shore D hardness value of 63, thus giving evidence of the effect of the thermoplastic elastomer on hardness. It is worth noting the balanced hardness of MLO-compatibilized PLA/SEBS blends with Shore D values of 58.8.

\subsection{Morphology of PLA/SEBS Blends}

Mechanical properties of uncompatibilized and compatibilized PLA/SEBS blends are directly related to their internal structure. Figure 2 gathers the field emission scanning electron microscopy (FESEM) images at $500 \times$ of uncompatibilized and compatibilized PLA/SEBS blends after the impact test. 

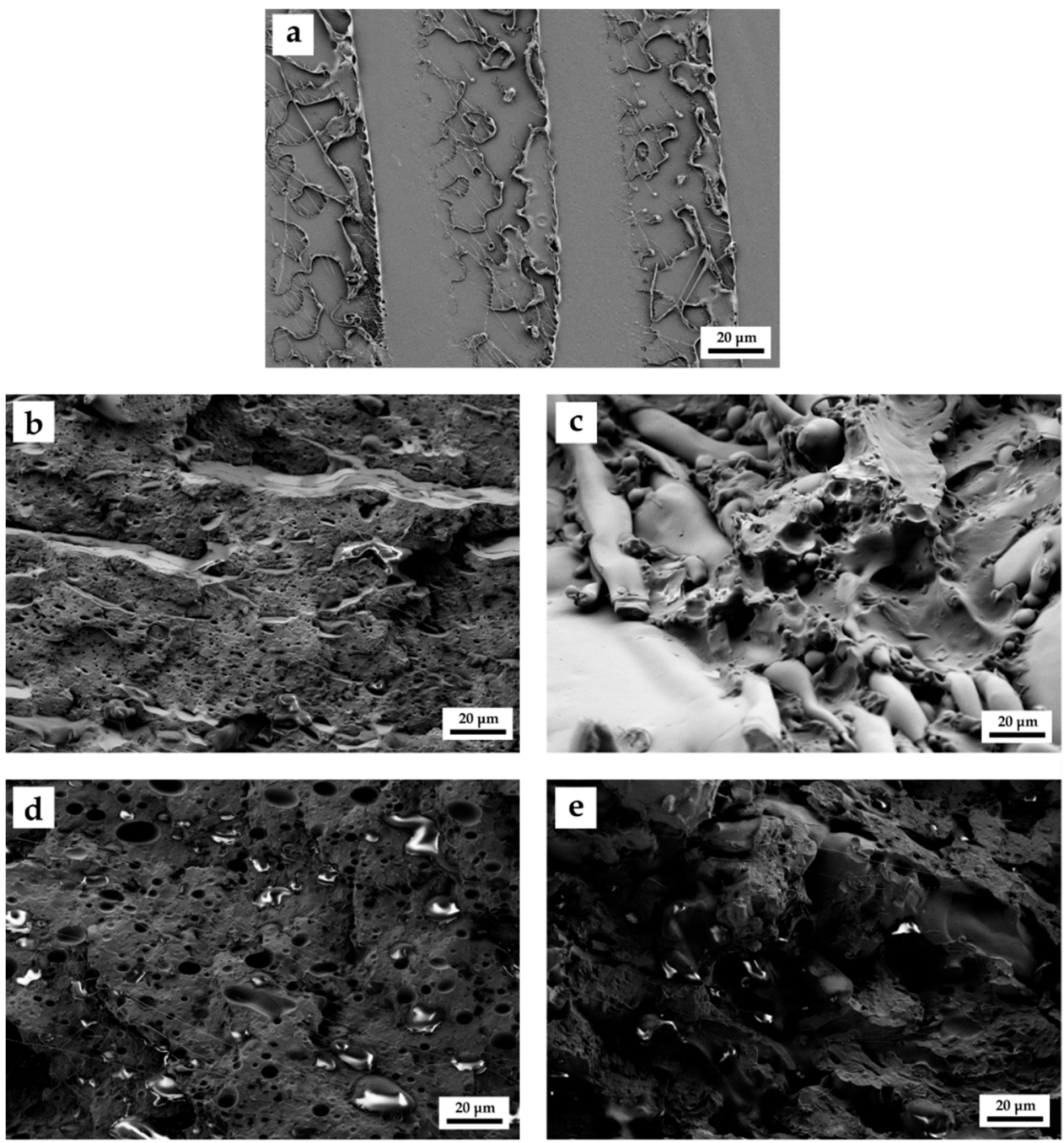

Figure 2. Field emission scanning electron microscopy (FESEM) images at $500 \times$ of the fractured surfaces of the different uncompatibilized and compatibilized PLA/SEBS (20 wt.\%): (a) neat PLA; (b) uncompatibilized; (c) compatibilized with SEBS-g-MA; (d) compatibilized with MLO; (e) compatibilized with SEBS- $g$-MA/MLO.

Figure 2a shows the typical fracture surface of neat PLA, with a very flat surface (without plastic deformation) representative of high brittleness. A fractured brittle surface seems to be a polished surface with very low roughness since plastic deformation is not allowed to occur. Fracture starts with some microcracks in micropores and microvoids which can grow in the longitudinal (fracture plane) direction since plastic deformation is restricted. This crack formation-growing process takes place in several parts of the crosssection (the weakest parts) and, since there is very low plastic deformation, fracture occurs leading to a mirror finish surface with evidence of the crack formation and growth, as can be seen in Figure 2a. Immiscibility of the binary PLA/SEBS system is evidenced in Figure $2 b$ in which SEBS spherical or elliptical domains are finely dispersed and embedded into the PLA matrix. This morphology is the typical droplet-like corresponding to immiscible polymer blends. As can be seen, a high number of spherical voids can be detected in Figure $2 b$, which is attributed to the pulled SEBS particles during the impact test. In addition to the droplet-like morphology, there are poor polymer-polymer interface phenomena which result in poor mechanical properties as shown in Table 1. This poor polymer-polymer interface adhesion does not allow good load transfer and, consequently, the cohesion properties (tensile strength, elongation at break) are not improved in the uncompatibilized PLA/SEBS blend regarding neat PLA; despite this, the impact strength increases due to the rubber-like behaviour of the finely dispersed SEBS microparticles. Nehra et al. [55] 
reported similar morphologies for PLA/SEBS-g-MA blends and the stress concentration effect due to the poor polymer-polymer interactions.

The morphologies of the compatibilized PLA/SEBS blends are remarkably different from those described to date. In general, higher phase continuity can be detected and, subsequently, the number of voids is reduced, while their size is increased. With regard to the MLO-compatibilized systems (Figure 2d), phase separation is still detectable; nevertheless, the spherical voids, representative for the SEBS phase, are more deformed. This could be related to the plasticization effect that MLO provides to the blend, which allows higher plastic deformation. Hence, this morphology is in accordance with the previous mechanical properties. Ferri et al. [57] reported similar morphologies in PLA/TPS blends with different MLO content. Finally, Figure 2e shows the morphology of the mixture with SEBS- $g$-MA and MLO. This mixture gives a break between the MLO and the SEBS- $g$-MA separately, showing a rather rough surface with a good interaction between PLA and SEBS. These results are very much in line with the mechanical properties.

\subsection{Thermal Properties of PLA/SEBS Blends}

With regard to neat PLA, as the used grade is amorphous, which is typically used in films and sheets, it only shows its glass transition temperature $\left(T_{g}\right)$, located at $60-65{ }^{\circ} \mathrm{C}$ in a similar way to that described by Kaczmarek et al. [58]. Table 2 gathers the glass transition temperatures $\left(T_{g}\right)$ of the PLA-rich phase obtained by DSC (inflection point). As can be seen, neat PLA is characterized by a $T_{g}$ of $62.8^{\circ} \mathrm{C}$, and this is slightly reduced by blending it with SEBS without any compatibilizer. This is representative of very restricted compatibility/miscibility between these two polymers, as occurs with other systems such as that reported by Tjong et al. [56] in PP/SEBS composites with short glass fiber. The effect of SEBS- $g$-MA compatibilizer on $T_{g}$ of PLA-rich phase is almost negligible. It is MLO which gives the lowest $T_{g}$ compared to the other compatibilizing systems, with a value of $59.8^{\circ} \mathrm{C}$, which could be related to the increase in the free volume that the modified triglyceride structure provides to the blend, thus giving slightly increased chain mobility [52]. This reduction is still very low and indicates poor plasticization effects. Nevertheless, MLO can interact with both polymers in the blend. On one hand, some hydrophobic segments contained in MLO can interact with the ethylene-butylene soft segments, while the grafted maleic anhydride can react with the terminal hydroxyl groups of PLA as shown in Figure 1. Therefore, although MLO can provide different effects to polymer blends and composites, i.e., chain extension, branching, plasticization, compatibilization, crosslinking, among others, in this case, it seems that plasticization is very restricted and, due to the excellent impact strength of the MLO-compatibilized PLA/SEBS blend, it is possible to say that the compatibilization effect is more pronounced than others.

Table 2. Glass transition temperature $\left(T_{g}\right)$ of the PLA-rich phase in PLA/SEBS blends with different compatibilizers, obtained by differential scanning calorimetry (DSC).

\begin{tabular}{cc}
\hline Code & $T_{g}\left({ }^{\circ} \mathrm{C}\right)$ \\
\hline PLA & $62.8 \pm 0.5$ \\
PLA/SEBS & $61.9 \pm 0.3$ \\
PLA/SEBS/SEBS-g-MA & $61.8 \pm 0.4$ \\
PLA/SEBS/MLO & $59.8 \pm 0.2$ \\
PLA/SEBS/SEBS- $g$-MA-MLO & $60.9 \pm 0.1$ \\
\hline
\end{tabular}

The thermal degradation of PLA/SEBS is also slightly changed by using different compatibilizing systems as can be seen in Figure 3 with the corresponding TGA and first derivative (DTG) curves. The main quantitative parameters from the thermal degradation are summarized in Table 3. PLA possesses good thermal stability. In particular, its characteristic temperature for a $5 \mathrm{wt} . \%$ mass loss $\left(T_{5} \%\right.$ is close to $322{ }^{\circ} \mathrm{C}$, while the maximum degradation rate temperature $\left(T_{d e g}\right)$ is $368.9^{\circ} \mathrm{C}$. As reported in other studies, PLA degrades in a single step process with a residual mass of $0.3 \mathrm{wt} . \%$ [59]. SEBS addition to PLA leads 
to a slight decrease in the thermal stability of PLA/SEBS blends. The characteristic $T_{5} \%$ is reduced by almost $10^{\circ} \mathrm{C}$ down to $312{ }^{\circ} \mathrm{C}$, while the maximum degradation rate is also lower than neat PLA $\left(365.3^{\circ} \mathrm{C}\right)$. Similar effects of SEBS on thermal degradation have been reported in other systems consisting of poly(propylene) (PP and poly(styrene) (PS) blends as shown by Parameswaranpillai et al. [34].

a

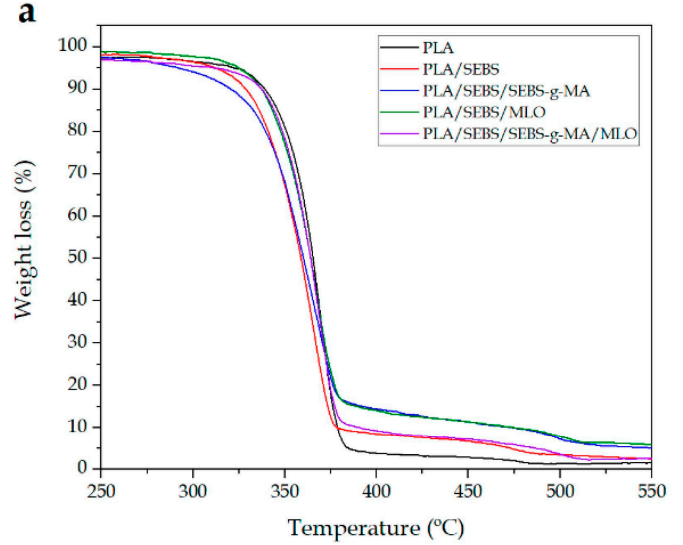

b

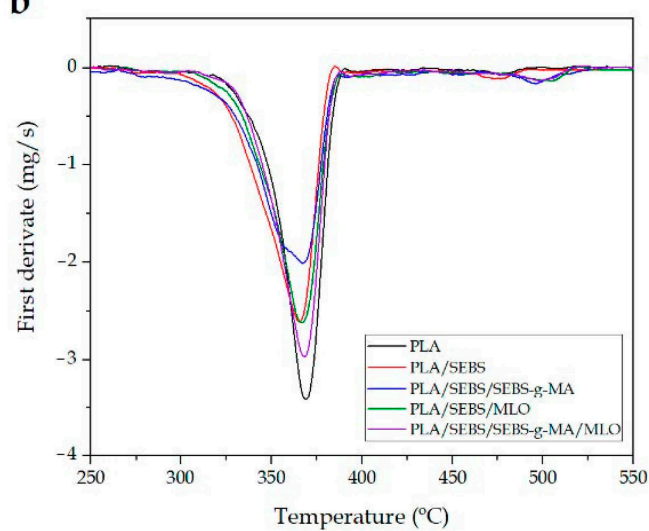

Figure 3. (a) Thermogravimetric analysis (TGA) curves and (b) first derivative (DTG) of PLA/SEBS blends with different compatibilizers.

Table 3. Main thermal degradation parameters of the PLA/SEBS blends with different compatibilizers in terms of the onset degradation temperature at a mass loss of $5 \mathrm{wt} \%\left(T_{5} \%\right)$, maximum degradation rate (peak) temperature $\left(T_{d e g}\right)$ and residual mass at $600{ }^{\circ} \mathrm{C}$.

\begin{tabular}{cccc}
\hline Code & $\boldsymbol{T}_{\mathbf{5 \%}}\left({ }^{\circ} \mathbf{C}\right)$ & $\boldsymbol{T}_{\text {deg }}\left({ }^{\circ} \mathbf{C}\right)$ & Residual Weight (\%) \\
\hline PLA & $322.8 \pm 1.5$ & $368.9 \pm 2.2$ & $0.3 \pm 0.1$ \\
PLA/SEBS & $312.3 \pm 1.2$ & $365.3 \pm 1.7$ & $0.4 \pm 0.1$ \\
PLA/SEBS/SEBS-g-MA & $291.8 \pm 1.1$ & $367.1 \pm 1.5$ & $0.6 \pm 0.2$ \\
PLA/SEBS/MLO & $324.8 \pm 1.5$ & $366.8 \pm 1.8$ & $0.3 \pm 0.2$ \\
PLA/SEBS/SEBS-g-MA/MLO & $312.4 \pm 1.1$ & $368.1 \pm 0.9$ & $0.2 \pm 0.1$ \\
\hline
\end{tabular}

The most relevant change can be observed by using SEBS- $g$-MA as a compatibilizing system for the base PLA/SEBS blend. The onset degradation temperature, measured as the $T_{5 \%}$, decreases to $291.8^{\circ} \mathrm{C}$, which is $30^{\circ} \mathrm{C}$ lower than neat PLA. Chow et al. [60] reported similar behaviour and attributed this decrease in the thermal stability to thermooxidative degradation of ethylene-butylene-styrene segments, triggered in short-length segment hydrocarbons. It is worth noting that SEBS- $g$-MA compatibilized PLA/SEBS blends show a small hump comprised in the $380-500{ }^{\circ} \mathrm{C}$ range. This is due to the use of air atmosphere during TGA characterization. As suggested by Chow et al. [60], the maleic anhydride (MA) groups grafted to SEBS can readily react with oxygen at room temperature, thus leading to free radical formation. These free radicals could boost the degradation process and, subsequently, the thermal stability of the PLA/SEBS blends compatibilized with SEBS-gMA is lower.

With regard to the MLO-compatibilized PLA/SEBS blends, it seems that MLO contributes to a slight thermal degradation stabilization or, at least, does not worsen the base values. In fact, the $T_{5 \%}$ is increased by $2{ }^{\circ} \mathrm{C}$ with regard to PLA and by $12{ }^{\circ} \mathrm{C}$ with regard to the uncompatibilized PLA/SEBS blend. MLO, as other modified vegetable oils, can exert different effects on polymer blends and composites. Some of them are compatibilization and/or crosslinking, which have a positive effect on the thermal stability.

\subsection{Dynamic-Mechanical Behaviour of PLA/SEBS Blends}

Figure 4 gathers the dynamical-mechanical behaviour of neat PLA and uncompatibilized/compatibilized PLA/SEBS blends. Figure 4a shows the plot evolution of the 
storage modulus $\left(E^{\prime}\right)$ and loss modulus $\left(E^{\prime \prime}\right)$ as a function of temperature. Neat PLA shows the typical behaviour of a rigid polymer, with a $E^{\prime}$ value of $2100 \mathrm{MPa}$ at $-100{ }^{\circ} \mathrm{C}$, which is dramatically reduced down to $35 \mathrm{MPa}$ at $100{ }^{\circ} \mathrm{C}$ (above its $T_{g}$ ). At about $70{ }^{\circ} \mathrm{C}$, it is possible to observe a dramatic drop in the storage modulus, which is attributed to the $\alpha$-relaxation process of PLA, or its glass transition temperature $\left(T_{g}\right)$. These characteristic values obtained for PLA agree with other DMTA properties of PLA reported in literature with a $T_{g}$ in the $60-70{ }^{\circ} \mathrm{C}$ range and a storage modulus, $E^{\prime}$ of $1500-2200 \mathrm{MPa}$, depending on the PLA grade [61,62]. Furthermore, in relation to the tan $\delta$ values, Lascano et al. [63] showed very similar results to those obtained in this work.
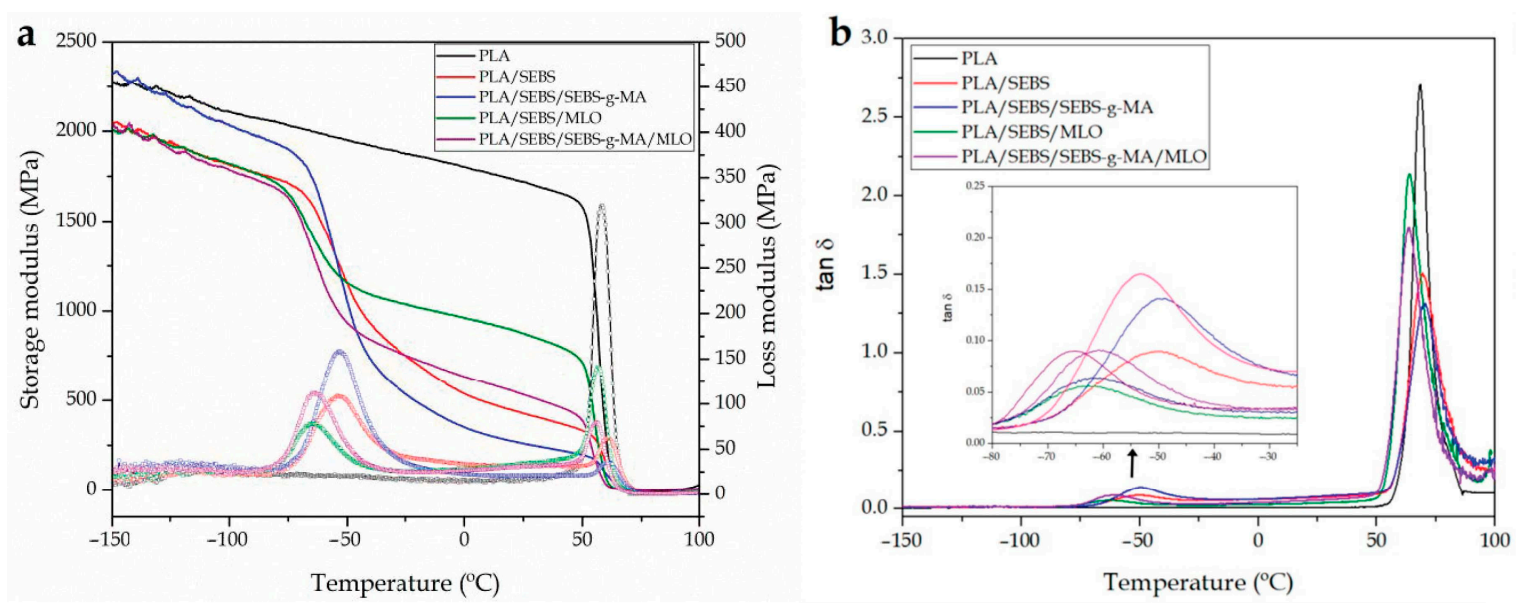

Figure 4. Plot evolution of (a) the storage modulus (Line) (E')/Loss modulus (Line + Symbol) (E") and (b) the dynamic damping factor $(\tan \delta)$ of the injection-molded samples of PLA/SEBS blends with different compatibilizers.

The addition of SEBS provides a remarkable change in the stiffness, as previously described regarding mechanical properties. As can be seen in Figure 4a, the DMTA curve for the uncompatibilized PLA/SEBS blends offers two main drops in the storage modulus. The first one is located at about $-50{ }^{\circ} \mathrm{C}$ and is directly related to the glass transition temperature, $T_{g}$ of SEBS. This drop is responsible for the low storage modulus (low rigidity) values at room temperature for all PLA/SEBS blends, as observed previously on tensile properties. The second relevant drop in the storage modulus is located at about $60-70{ }^{\circ} \mathrm{C}$ and is related to the glass transition temperature of the PLA-rich phase. Guo et al. [64] also reported a significant decrease in poly(propylene) stiffness by adding SEBS, which is in accordance with the results obtained herein. On the other hand, there is not a remarkable shift in the characteristic $T_{g}$ values of the PLA- and SEBS-rich phases, thus giving evidence of the immiscibility of both polymers. As Figure 4a suggests, PLA and SEBS offer very restricted miscibility since the corresponding $T_{g}$ values do not change in a noticeable way, as observed in Table 4, with some mechanical properties obtained by DMTA. By taking the $T_{g}$ at the maximum value of $\tan \delta$ (peak maximum criterion), the $T_{g}$ of the PLA-rich phase is $68.5^{\circ} \mathrm{C}$, while this PLA-rich phase shows a $T_{g}$ of $69.3^{\circ} \mathrm{C}$ in the uncompatibilized blend. Nevertheless, the use of maleinized SEBS (SEBS- $g$-MA) has been reported to provide a slight decrease in the $T_{g}$ of PLA-rich phase. Nehra et al. [55] reported a decrease in the $T_{g}$ of PLA from 82.4 to $74.1^{\circ} \mathrm{C}$ (with the $\tan \delta$ peak maximum criterium). Nevertheless, they used 20 wt. \% SEBS- $g$-MA in the blends with PLA. In this work, the amount of SEBS- $g$-MA is noticeably lower and, subsequently, it does not provide a remarkable change in the $T_{g}$ of the PLA-rich phase as can be seen in Table 4 with values close to $70^{\circ} \mathrm{C}$. As observed in previous techniques, it is MLO which provides a slight decrease in the characteristic $T_{g}$ value of PLA-rich phase down to values of $63.8^{\circ} \mathrm{C}$. This decrease was also observed by DSC characterization and can be ascribed to a slight plasticization effect of MLO, thus confirming that PLA provides a slight increase in chain mobility whit the subsequent decrease in $T_{g}$ [65]. Another striking issue is that the storage modulus of all compositions is maintained at high values at $-100{ }^{\circ} \mathrm{C}$ (below both $T_{g}$ corresponding to the PLA-rich 
and SEBS-rich phases). Nevertheless, at room temperature (above the $T_{g}$ of the SEBS-rich phase and below the $T_{g}$ of the PLA-rich phase), the differences are much higher due to the softening of the elastomer component in the blend and are in total agreement with the tensile modulus obtained by tensile tests as above-mentioned. Similar behaviour has been reported in immiscible PE/PLA blends with different reactive compatibilizers [66].

Table 4. Dynamic-mechanical properties of injection-moulded samples of PLA/SEBS blends with different compatibilizers, at different temperatures.

\begin{tabular}{ccccc}
\hline Parts & $\boldsymbol{E}^{\prime} \mathbf{( M P a )}$ at $-\mathbf{1 0 0}{ }^{\circ} \mathbf{C}$ & $\left.\boldsymbol{E}^{\prime} \mathbf{( M P a}\right)$ at $\mathbf{2 5}{ }^{\circ} \mathbf{C}$ & $\boldsymbol{E}^{\prime}(\mathbf{M P a})$ at 100 ${ }^{\circ} \mathbf{C}$ & $\boldsymbol{T}_{\boldsymbol{g} P L A}\left({ }^{\circ} \mathbf{C}\right){ }^{*}$ \\
\hline PLA & $2110 \pm 28$ & $1720 \pm 14$ & $35.3 \pm 1.1$ & $68.5 \pm 0.8$ \\
PLA/SEBS & $1815 \pm 17$ & $427 \pm 8$ & $4.9 \pm 0.3$ & $69.3 \pm 0.9$ \\
PLA/SEBS/SEBS-g-MA & $2030 \pm 30$ & $260 \pm 7$ & $3.1 \pm 0.2$ & $70.0 \pm 0.8$ \\
PLA/SEBS/MLO & $1780 \pm 17$ & $875 \pm 10$ & $5.9 \pm 0.6$ & $63.8 \pm 0.8$ \\
PLA/SEBS/SEBS-g-MA/MLO & $1780 \pm 25$ & $265 \pm 12$ & $8.1 \pm 0.3$ & $63.7 \pm 1.1$ \\
\hline
\end{tabular}

* The $T_{g}$ was measured using the $\tan \delta$ peak maximum criterion.

\subsection{Colour Measurement and Wetting Properties of PLA/SEBS Blends}

Colour, luminance and transparency are essential issues to be considered in packaging, as the consumer's impression of the product depends on them. Table 5 shows the values of the colour coordinates of PLA/SEBS blends, while Figure 5 shows the visual appearance of the tensile test specimens. Neat PLA exhibits clear transparency due to its amorphous structure as confirmed by DSC [67]. Moreover, when using the different compatibilization systems, transparency is lost, probably due the lack of miscibility between both polymers [67].

Table 5. Luminance and colour coordinates $\left(L^{*} a^{*} b^{*}\right)$ of the PLA/SEBS blends with different compatibilizers.

\begin{tabular}{ccccc}
\hline Code & $\boldsymbol{L}^{*}$ & $\boldsymbol{a}^{*}$ & $\boldsymbol{b}^{*}$ & Yellowness Index (YI) \\
\hline PLA & $40.7 \pm 0.3$ & $-0.45 \pm 0.03$ & $4.71 \pm 0.13$ & $21.3 \pm 0.3$ \\
PLA/SEBS & $53.2 \pm 0.1$ & $1.42 \pm 0.01$ & $6.76 \pm 0.06$ & $26.3 \pm 0.1$ \\
PLA/SEBS/SEBS-g-MA & $59.3 \pm 0.1$ & $-0.82 \pm 0.02$ & $5.57 \pm 0.10$ & $19.3 \pm 0.1$ \\
PLA/SEBS/MLO & $58.4 \pm 0.3$ & $-2.36 \pm 0.02$ & $8.69 \pm 0.18$ & $25.2 \pm 0.3$ \\
PLA/SEBS/SEBS-g-MA-MLO & $61.1 \pm 0.1$ & $-1.74 \pm 0.01$ & $9.94 \pm 0.02$ & $28.1 \pm 0.1$ \\
\hline
\end{tabular}




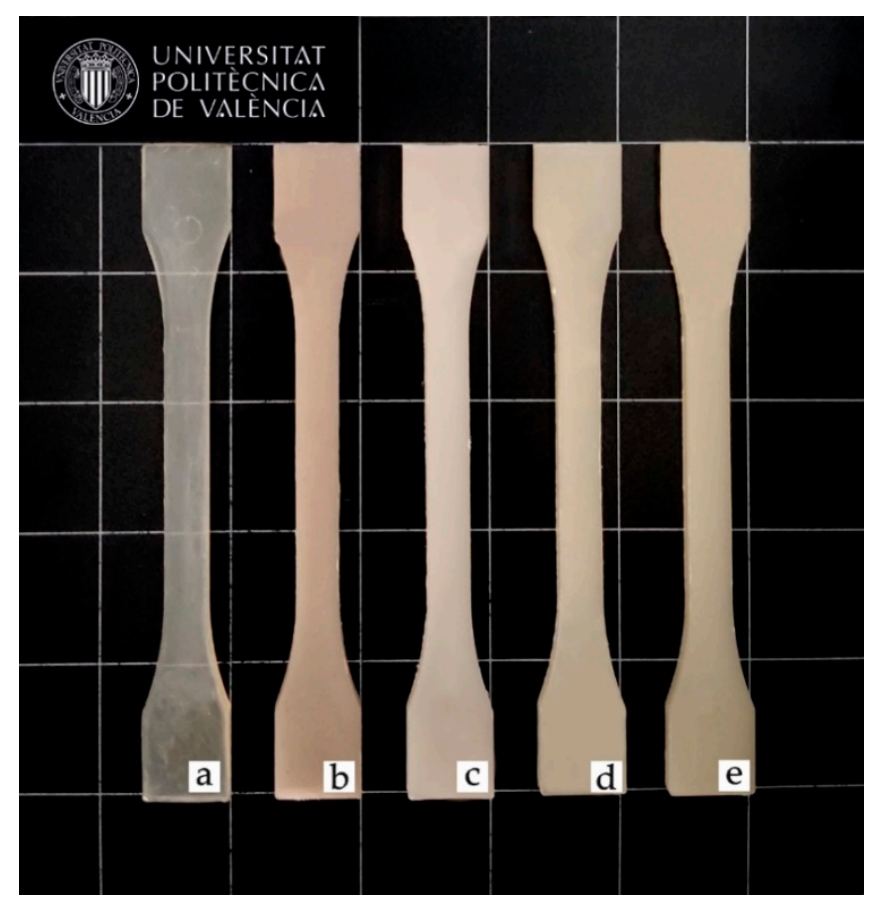

Figure 5. Visual appearance of the samples: (a) neat PLA; (b) uncompatibilized PLA/SEBS; (c) PLA/SEBS compatibilized with SEBS-g-MA; (d) PLA/SEBS compatibilized with MLO; (e) PLA/SEBS compatibilized with SEBS- $g$-MA and MLO.

Colour coordinates $L^{*} a^{*} b^{*}$ were measured on injection-moulded samples. Luminance $\left(L^{*}\right)$ refers to the clarity or lightness. There seems to be little change in the studied samples, although the addition of compatibilizers in PLA/SEBS blends provides slight yellowing, especially in cases where MLO is used as a compatibilizing system. Regarding the $a^{*}$ colour coordinate, it indicates the colour change between green (negative) and red (positive). All samples show negative values, except that corresponding to the uncompatibilized PLA/SEBS blend, which shows a slight yellow-to-brown colour. All registered $a^{*}$ values are close to 0 , due to the white shade of the samples, although it can be seen as the addition of compatibilizers that brings those values near to the negative region, and therefore, towards green shades, especially in samples with MLO. Quiles-Carrillo et al. [68] observed a similar change in colour in PA1010-based materials with MLO. Concerning the $b^{*}$ coordinate, it is indicative of the yellow (positive) and blue (negative) region. All studied materials exhibit positive values, due to their yellowish-white colour, and brown in the case of PLA/SEBS. All used compatibilizers increase the $b^{*}$ coordinate, thus indicating some yellowing. This is particularly pronounced in MLO-compatibilized PLA/SEBS blends, with $b^{*}$ values close to 10 , which is consistent with the visual aspect. It is important to bear in mind the intrinsic yellow colour of MLO. This deviation towards more yellow tones is directly reflected in the yellowness index shown in Table 5. Yellowness is associated with an increase in chromophore groups, whose conjugation causes absorption at higher wavelengths. In particular, the blends containing MLO cause the greatest yellowing in the samples. This index has a great advantage from the point of view of the packaging of certain elements, allowing better protection against light [69].

On the one hand, the opacity and slight yellow colour of PLA/SEBS blends could represent a disadvantage in certain packaging sectors, where transparency is required, but on the other hand, they could be an advantage when it comes to preventing UV radiation from harming sensitive products, as could be the case for food and pharmaceutical industries [70]. So, opaque PLA/SEBS blends can act as a barrier against food degradation provoked by UV radiation. Barreto et al. reported the effectiveness of SEBS as a protective agent against UV radiation when used as compatibilizer [71]. 
The water contact angle $\left(\theta_{w}\right)$ of neat PLA and PLA/SEBS blends with different compatibilizers was obtained to evaluate their wetting properties. A high $\theta_{w}$ is representative of poor surface affinity to water. As can be seen in Figure 6, all samples present contact angles far superior to $65^{\circ}$, which could be considered the hydrophobicity threshold [72]. Although PLA has some polar groups in its structure, it is a hydrophobic polymer with a $\theta_{w}$ of $85.2^{\circ}$. The addition of SEBS and SEBS- $g$-MA slightly increases the hydrophobicity of PLA up to values of $88.8^{\circ}$ and $92.8^{\circ}$, respectively. It is worth noting that SEBS is a highly hydrophobic terpolymer, as Fang et al. reported [73]. With regard to MLO, it does not provide a remarkable change in the wetting properties, while the combined effect of MLO and SEBS- $g$-MA leads to a slightly higher $\theta_{w}$ of $89.5^{\circ}$.

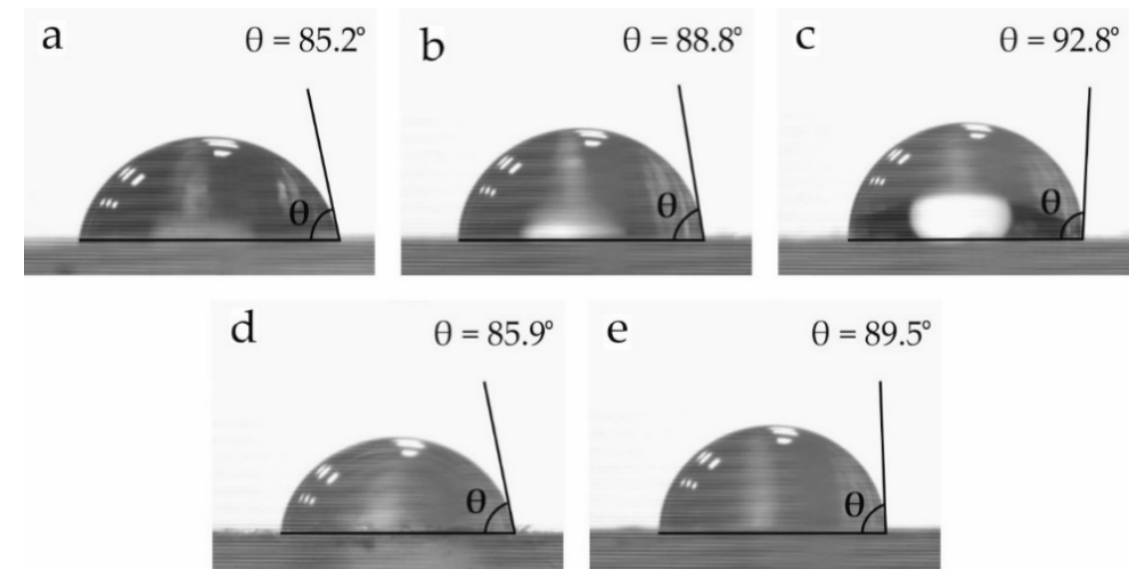

Figure 6. Water contact angle of the samples: (a) neat PLA; (b) uncompatibilized PLA/SEBS; (c) PLA/SEBS compatibilized with SEBS- $g$-MA; (d) PLA/SEBS compatibilized with MLO; (e) PLA/SEBS compatibilized with SEBS- $g$-MA and MLO.

\section{Materials and Methods}

\subsection{Materials}

The base poly(lactic acid) was an Ingeo ${ }^{\mathrm{TM}} 2003 \mathrm{D}$ commercial grade, supplied by Natureworks (Minnetonka, MN, USA). This PLA grade has a density of $1.24 \mathrm{~g} / \mathrm{cm}^{3}$ and a melt flow index (MFI) of $6 \mathrm{~g} / 10 \mathrm{~min}$ (measured at $210^{\circ} \mathrm{C}$ and a load of $2.16 \mathrm{~kg}$ ). This PLA grade offers high transparency and finds applications in the food-packaging sector. The impact modifier was a polystyrene- $b$-poly(ethylene-ran-butylene)- $b$-polystyrene terpolymer, SEBS, with an extremely low hardness (Shore A hardness $=5$ ) grade Megol TA $5{ }^{\circledR}$ Neutral. This was supplied by Applicazioni Plastiche Industriali (Api SpA, Vicenza, Italy) and has a density of $0.88-0.89 \mathrm{~g} / \mathrm{cm}^{3}$. It has an extremely low tensile modulus (1.1-4.2 $\mathrm{MPa}$ at $100 \%$ elongation) and low tensile strength $(<6 \mathrm{MPa})$.

Different compatibilizers with grafted maleic anhydride were selected to improve the toughness of PLA/SEBS blends. One of them was a polystyrene- $b$-poly(ethylene-ranbutylene)- $b$-polystyrene-graft-maleic anhydride terpolymer (SEBS- $g$-MA) with CAS number $124578-11-6$ and a melt index of $21 \mathrm{~g} / 10 \mathrm{~min}\left(230^{\circ} \mathrm{C} / 5.0 \mathrm{~kg}\right)$ and was supplied by Sigma Aldrich S.A. (Madrid, Spain). An environmentally friendly maleinized linseed oil (MLO), VEOMER LIN, was supplied by Vandeputte (Mouscron, Belgium). This modified vegetable oil possesses a viscosity of $10 \mathrm{dPa} s$ at $20^{\circ} \mathrm{C}$ and an acid value of $105-130 \mathrm{mg} \mathrm{KOH} / \mathrm{g}$. Figure 7 shows the chemical structure of the different polymers and compatibilizers used in this work. 
BASE POLYMERS<smiles>CC(C)C(C)C(=O)C(C)C(C)(C)C</smiles>

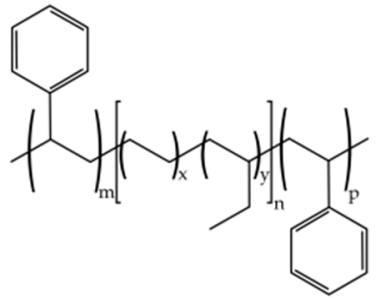

polylactide - (PLA) polystyrene-block-(ethylene-ran-butylene)-block-styrene - (SEBS)

\section{COMPATIBILIZERS}

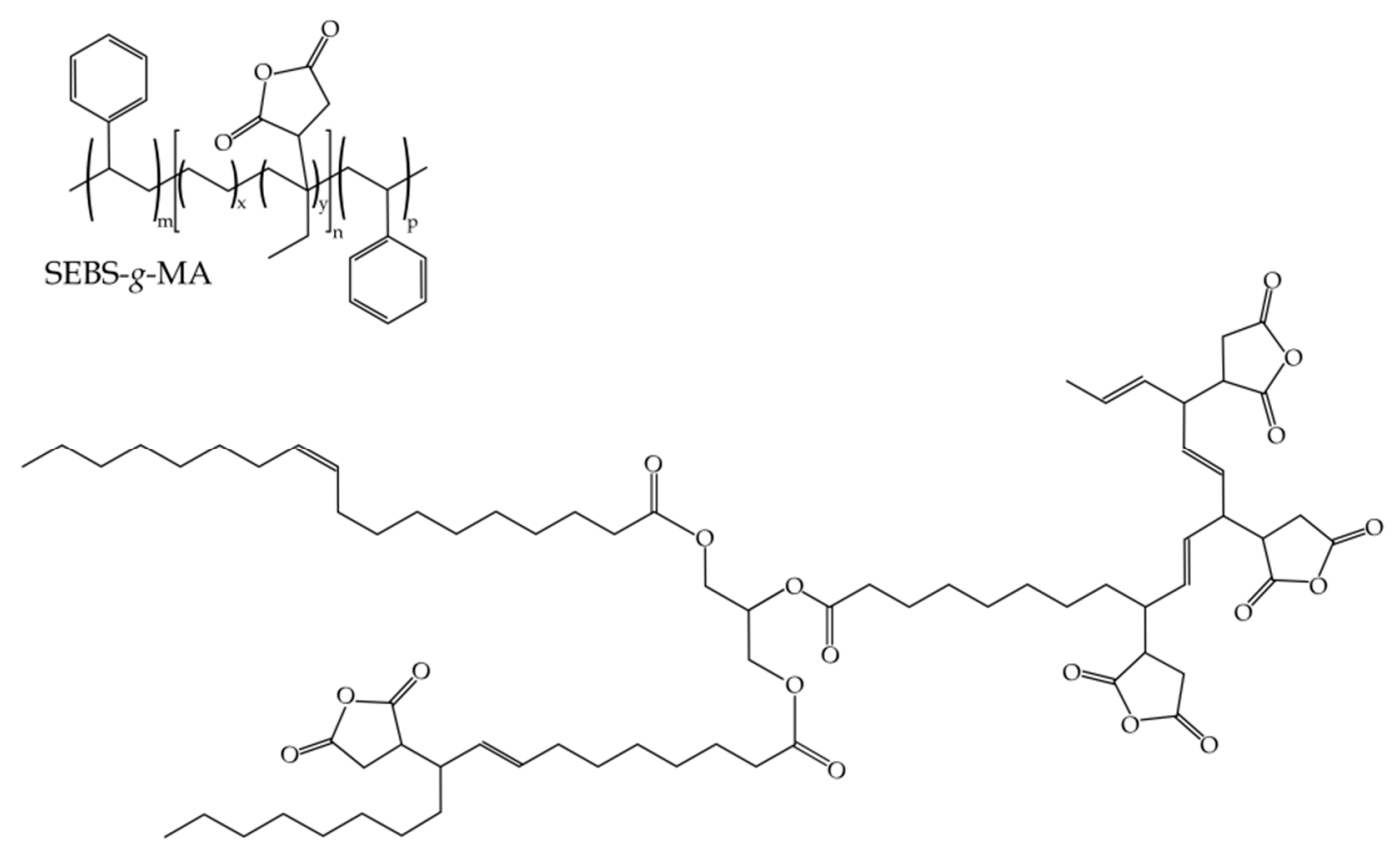

maleinized linseed oil (MLO)

Figure 7. Chemical structure of the base polymer and the different compatibilizers used in this work.

\subsection{Preparation of PLA/SEBS Blends}

PLA and SEBS were initially dried at $40^{\circ} \mathrm{C}$ for $48 \mathrm{~h}$ in a dehumidifying dryer MDEO to remove any residual moisture prior to processing. Then, the corresponding wt. $\%$ of each component (see Table 6) was mixed and pre-homogenized in a zipper bag.

Table 6. Summary of compositions according to the weight content (wt.\%) of PLA/SEBS and different compatibilizers.

\begin{tabular}{ccccc}
\hline Code & PLA (wt. $\%)$ & SEBS (wt. $\%)$ & SEBS-g-MA (wt. $\%)$ & MLO $(\mathbf{p h r})$ \\
\hline PLA & 100 & 0 & 0 & 0 \\
PLA/SEBS & 80 & 20 & 0 & 0 \\
PLA/SEBS/SEBS-g-MA & 80 & 18 & 2 & 0 \\
PLA/SEBS/MLO & 80 & 20 & 0 & 5 \\
PLA/SEBS/SEBS-g-MA/MLO & 80 & 19 & 1 & 2.5 \\
\hline
\end{tabular}

The corresponding formulations were compounded in a twin-screw extruder from Construcciones Mecánicas Dupra, S.L. (Alicante, Spain). This extruder has a $25 \mathrm{~mm}$ diameter with a length-to-diameter ratio (L/D) of 24 . The extrusion process was carried out at a rate of $18 \mathrm{rpm}$, using the following temperature profile (from the hopper to the die): $175-180-190-195^{\circ} \mathrm{C}$. The compounded materials were pelletized using an air-knife 
unit. In all cases, residence time was approximately $1 \mathrm{~min}$. Table 6 shows the compositions of the materials developed in this work.

To transform the pellets into standard samples, a Meteor 270/75 injection moulding machine from Mateu \& Solé (Barcelona, Spain) was used. The temperature profile in the injection moulding unit was 175 (hopper), 180, 190 and $195{ }^{\circ} \mathrm{C}$ (injection nozzle). A clamping force of 75 tons was applied, while the cavity filling and cooling times were set to 1 and $10 \mathrm{~s}$, respectively. Standard samples for mechanical and thermal characterization with an average thickness of $4 \mathrm{~mm}$ were obtained.

\subsection{Characterization of PLA/SEBS Blends}

3.3.1. Mechanical Characterization

Tensile properties of PLA/SEBS blends were obtained in a universal testing machine ELIB 50 from S.A.E. Ibertest (Madrid, Spain) as recommended by ISO 527-1:2012. A 5-kN load cell was used and the cross-head speed was set to $5 \mathrm{~mm} / \mathrm{min}$. Shore hardness was measured in a 676-D durometer from J. Bot Instruments (Barcelona, Spain), using the D-scale, on rectangular samples with dimensions $80 \times 10 \times 4 \mathrm{~mm}^{3}$, according to ISO 868:2003. The impact strength was also studied on injection-moulded rectangular samples with dimensions of $80 \times 10 \times 4 \mathrm{~mm}^{3}$ in a Charpy pendulum (1-J) from Metrotec S.A. (San Sebastián, Spain) on notched samples ( $0.25 \mathrm{~mm}$ radius V-notch), following the specifications of ISO 179-1:2010. All mechanical characterizations were performed at room temperature, and a minimum of 6 specimens of each blend formulation were tested, and the characteristic values were averaged. For tensile tests, the tensile modulus $(E)$, the percentage elongation at break $\left(\% \varepsilon_{b}\right)$ and the maximum tensile strength $\left(\sigma_{\max }\right)$ were obtained. The impact strength was obtained from Charpy tests, and the Shore D hardness average values were obtained using the Shore D durometer.

\subsubsection{Morphology Characterization}

The morphology of the fractured samples from impact tests was studied by field emission scanning electron microscopy (FESEM) in a ZEISS ULTRA 55 microscope from Oxford Instruments (Abingdon, United Kingdom). Before placing the samples in the vacuum chamber, they were sputtered with a gold-palladium alloy in an EMITECH sputter coating SC7620 model from Quorum Technologies, Ltd. (East Sussex, UK). The FESEM was operated at an acceleration voltage of $2 \mathrm{kV}$.

\subsubsection{Thermal Analysis}

The most relevant thermal transitions of PLA/SEBS blends were obtained by differential scanning calorimetry (DSC) in a Mettler-Toledo 821 calorimeter (Schwerzenbach, Switzerland). Small rectangular-like samples with an approximate side length of 1-2 mm, with an average weight of 5-7 mg, were subjected to a thermal program divided into three stages: a first heating from 25 to $170{ }^{\circ} \mathrm{C}$ followed by a cooling to $0{ }^{\circ} \mathrm{C}$, and a second heating to $250^{\circ} \mathrm{C}$. Both heating and cooling rates were set to $10^{\circ} \mathrm{C} / \mathrm{min}$. All tests were run in nitrogen atmosphere with a flowrate of $66 \mathrm{~mL} / \mathrm{min}$ using standard sealed aluminium crucibles with a capacity of $40 \mu \mathrm{L}$.

The thermal degradation of the PLA/SEBS blends was assessed by thermogravimetric analysis (TGA). TGA tests were performed in a LINSEIS TGA 1000 (Selb, Germany). Samples with a weight of 5-7.5 mg were placed in $70 \mu \mathrm{l}$ alumina crucibles and subjected to a dynamic heating program from 30 to $700{ }^{\circ} \mathrm{C}$ at a heating rate of $10{ }^{\circ} \mathrm{C} / \mathrm{min}$ in air atmosphere. The first derivative thermogravimetric (DTG) curves were also determined. All tests were carried out in triplicate to obtain reliable results, and the provided curves and thermograms correspond to the average of these three tests.

\subsubsection{Dynamical-Mechanical Thermal Characterization}

Dynamical-mechanical thermal analysis (DMTA) was carried out in a DMA1 dynamic analyzer from Mettler-Toledo (Schwerzenbach, Switzerland), working in single cantilever 
flexural conditions. Rectangular samples with dimensions $20 \times 6 \times 2.7 \mathrm{~mm}^{3}$ were subjected to a dynamic temperature sweep from -150 to $120^{\circ} \mathrm{C}$ at a constant heating rate of $2{ }^{\circ} \mathrm{C} / \mathrm{min}$. The selected frequency was $1 \mathrm{~Hz}$, and the maximum flexural deformation or cantilever deflection was set to $10 \mu \mathrm{m}$. DMTA tests were run in triplicate and averaged.

\subsubsection{Colour and Wetting Characterization}

A Konica CM-3600d Colorflex-DIFF2, from Hunter Associates Laboratory, Inc. (Reston, Virginia, USA) was used for the colour measurement. Colour coordinates $\left(L^{*} a^{*} b^{*}\right)$ were measured according to the following criteria: $L^{*}=0$, darkness; $L^{*}=100$, lightness; $a^{*}$ represents the green $\left(a^{*}<0\right)$ to red $\left(a^{*}>0\right) ; b^{*}$ stands for the blue $\left(b^{*}<0\right)$ to yellow $\left(b^{*}>0\right)$ coordinate. The yellowness index for each sample was calculated according to ASTM E313. Colour measurements were carried out on standard tensile samples and, at least five different measurements of the colour coordinates were obtained and averaged.

Contact angle measurements were carried out with an EasyDrop Standard goniometer model FM140 (KRÜSS GmbH, Hamburg, Deutschland) which is equipped with a video capture kit and analysis software (Drop Shape Analysis SW21; DSA1). Double distilled water was used as test liquid. The wetting properties were evaluated on the surface of rectangular $80 \times 10 \times 4 \mathrm{~mm}^{3}$ samples. At least 10 measurements of the water contact angle were collected and averaged.

\subsubsection{Statistical Analysis}

The mechanical properties were evaluated through analysis of variance (ANOVA) using STATGRAPHICS Centurion XVI v 16.1.03 from StatPoint Technologies, Inc. (Warrenton, VA, USA). Fisher's least significant difference (LSD) was used at the $95 \%$ confidence level $(p<0.05)$. Mean values and standard deviations were also reported.

\section{Conclusions}

This work reports the development of polylactide (PLA) formulations with improved toughness by blending with a thermoplastic elastomer, namely, polystyrene- $b$-(ethyleneran-butylene)- $b$-styrene (SEBS) polymer. PLA/SEBS blends with $20 \mathrm{wt} \%$ SEBS can be processed by extrusion and subsequent injection moulding. The rubber-like nature of SEBS provides improved toughness to PLA. Neat PLA is a brittle material with an impact strength (Charpy) of $1.3 \mathrm{~kJ} / \mathrm{m}^{2}$, while its blend with $20 \mathrm{wt} . \%$ SEBS shows a remarkable increase in toughness with an impact strength of $4.8 \mathrm{~kJ} / \mathrm{m}^{2}$. Despite this, PLA/SEBS blends are immiscible as observed by field emission scanning electron microscopy (FESEM) and thermal analysis characterization. To improve the impact strength, two different maleinized compounds were used: one petroleum-derived compound polystyrene- $b$ (ethylene-ran-butylene)-b-styrene-graft-maleic anhydride (SEBS-g-MA) and one biobased maleinized triglyceride from linseed, namely, maleinized linseed oil (MLO). The best results in terms of impact strength were obtained with $5 \mathrm{phr}$ MLO addition with an impact strength of $6.1 \mathrm{~kJ} / \mathrm{m}^{2}$. Moreover, MLO also contributes to increasing the low elongation at break of neat PLA from $7.4 \%$ up to values of $50.2 \%$, thus showing the efficiency of this compatibilizer. In addition, MLO also provides slightly improved thermal stability, as thermogravimetric characterization has revealed. Dynamic mechanical thermal analysis (DMTA) also corroborated poor miscibility between PLA and SEBS since the corresponding $T_{g}$ of the PLA- and SEBS-rich phases remains almost invariable. The morphology of the PLA/SEBS blends was highly dependent on the compatibilizer system. While PLA offers a typical brittle flat surface, PLA/SEBS blends offer the characteristic immiscible morphology with a brittle PLA matrix in which SEBS microspheres (droplet like) are finely dispersed. The use of MLO leads to a change in the spherical SEBS domains to deformed shapes, thus indicating increased ductility properties. Overall, the results obtained in this work offer a cost-effective solution to partially overcome the intrinsic brittleness of PLA, thus broadening its potential applications in the packaging industry. 
Author Contributions: Conceptualization, R.B. and L.Q.-C.; methodology, N.M.; validation, N.M. and L.Q.-C.; investigation, R.T.-O., J.G.-C. and J.I.-M.; resources, R.B.; data curation, L.Q.-C.; writingoriginal draft preparation, L.Q.-C., R.T.-O. and J.G.-C.; writing-review and editing, R.B. and J.I.-M.; funding acquisition, R.B. All authors have read and agreed to the published version of the manuscript.

Funding: This research was funded by the Ministry of Science, Innovation, and Universities (MICIU) project number MAT2017-84909-C2-2-R.

Institutional Review Board Statement: Not applicable.

Informed Consent Statement: Not applicable.

Data Availability Statement: The data presented in this study are available in this article.

Acknowledgments: L.Q.-C. wants to thank Universitat Politècnica de València for his post-doctoral grant with reference number PAID-10-20/SP20200073. J.I.-M. wants to thank Universitat Politècnica de València for his FPI grant number PAID-01-19/SP20190011 and the Spanish Ministry of Science, Innovation and Universities for the FPU grant (FPU19/01759). J.G.-C. wants to thank Universitat Politècnica de València for his FPI grant number PAID-01-20/SP20200080.

Conflicts of Interest: The authors declare no conflict of interest.

\section{References}

1. Lascano, D.; Quiles-Carrillo, L.; Balart, R.; Boronat, T.; Montanes, N. Toughened poly (lactic acid)—PLA formulations by binary blends with poly (butylene succinate-co-adipate)_PBSA and their shape memory behaviour. Materials 2019, 12, 622. [CrossRef]

2. Kabir, E.; Kaur, R.; Lee, J.; Kim, K.-H.; Kwon, E.E. Prospects of biopolymer technology as an alternative option for non-degradable plastics and sustainable management of plastic wastes. J. Clean. Prod. 2020, 258, 120536.

3. Liminana, P.; Garcia-Sanoguera, D.; Quiles-Carrillo, L.; Balart, R.; Montanes, N. Development and characterization of environmentally friendly composites from poly(butylene succinate) (PBS) and almond shell flour with different compatibilizers. Compos. Part B Eng. 2018, 144, 153-162. [CrossRef]

4. Tahir, N.; Bhatti, H.N.; Iqbal, M.; Noreen, S. Biopolymers composites with peanut hull waste biomass and application for Crystal Violet adsorption. Int. J. Biol. Macromol. 2017, 94, 210-220. [CrossRef]

5. Quiles-Carrillo, L.; Montanes, N.; Lagaron, J.M.; Balart, R.; Torres-Giner, S. On the use of acrylated epoxidized soybean oil as a reactive compatibilizer in injection-molded compostable pieces consisting of polylactide filled with orange peel flour. Polymer International. 2018, 67, 1341-1351. [CrossRef]

6. Barlow, C.; Morgan, D. Polymer film packaging for food: An environmental assessment. Resour. Conserv. Recycl. 2013, 78, 74-80. [CrossRef]

7. Balart, J.F.; Garcia-Sanoguera, D.; Balart, R.; Boronat, T.; Sanchez-Nacher, L. Manufacturing and properties of biobased thermoplastic composites from poly(lactid acid) and hazelnut shell wastes. Polym. Compos. 2018, 39, 848-857. [CrossRef]

8. Sun, J.Y.; Shen, J.J.; Chen, S.K.; Cooper, M.A.; Fu, H.B.; Wu, D.M.; Yang, Z.G. Nanofiller Reinforced Biodegradable PLA/PHA Composites: Current Status and Future Trends. Polymers 2018, 10, 22. [CrossRef]

9. Meereboer, K.W.; Misra, M.; Mohanty, A.K. Review of recent advances in the biodegradability of polyhydroxyalkanoate (PHA) bioplastics and their composites. Green Chem. 2020, 22, 5519-5558. [CrossRef]

10. Ciofu, C.; Mazurchevici, S.-N.; Maldonado-Cortes, D.; Pena-Paras, L.; Correa, D.I.Q.; Nedelcu, D. Tribological behavior of PLA biodegradable materials used in the automotive industry. Int. J. Mod. Manuf. Technol. 2019, 11, 83-88.

11. Averous, L. Biodegradable multiphase systems based on plasticized starch: A review. J. Macromol. Sci. Polym. Rev. 2004, C44, 231-274. [CrossRef]

12. Garcia-Campo, M.J.; Quiles-Carrillo, L.; Masia, J.; Reig-Pérez, M.J.; Montanes, N.; Balart, R. Environmentally friendly compatibilizers from soybean oil for ternary blends of poly (lactic acid)-PLA, poly ( $\varepsilon$-caprolactone)-PCL and poly (3-hydroxybutyrate)-PHB. Materials 2017, 10, 1339.

13. Abd Alsaheb, R.A.; Aladdin, A.; Othman, N.Z.; Abd Malek, R.; Leng, O.M.; Aziz, R.; El Enshasy, H.A. Recent applications of polylactic acid in pharmaceutical and medical industries. J. Chem. Pharm. Res. 2015, 7, 51-63.

14. Leroy, A.; Ribeiro, S.; Grossiord, C.; Alves, A.; Vestberg, R.H.; Salles, V.; Brunon, C.; Gritsch, K.; Grosgogeat, B.; Bayon, Y. FTIR microscopy contribution for comprehension of degradation mechanisms in PLA-based implantable medical devices. J. Mater. Sci. Mater. Med. 2017, 28, 13. [CrossRef]

15. Nagarajan, V.; Mohanty, A.K.; Misratt, M. Perspective on Polylactic Acid (PLA) based Sustainable Materials for Durable Applications: Focus on Toughness and Heat Resistance. ACS Sustain. Chem. Eng. 2016, 4, 2899-2916. [CrossRef]

16. Bouzouita, A.; Samuel, C.; Notta-Cuvier, D.; Odent, J.; Lauro, F.; Dubois, P.; Raquez, J.M. Design of highly tough poly(l-lactide)based ternary blends for automotive applications. J. Appl. Polym. Sci. 2016, 133, 9. [CrossRef]

17. Pappu, A.; Pickering, K.L.; Thakur, V.K. Manufacturing and characterization of sustainable hybrid composites using sisal and hemp fibres as reinforcement of poly (lactic acid) via injection moulding. Ind. Crop. Prod. 2019, 137, 260-269. [CrossRef] 
18. Spinelli, G.; Lamberti, P.; Tucci, V.; Ivanova, R.; Tabakova, S.; Ivanov, E.; Kotsilkova, R.; Cimmino, S.; Di Maio, R.; Silvestre, C. Rheological and electrical behaviour of nanocarbon/poly(lactic) acid for 3D printing applications. Compos. Part B Eng. 2019, 167, 467-476. [CrossRef]

19. Cisneros-López, E.; Pal, A.; Rodriguez, A.; Wu, F.; Misra, M.; Mielewski, D.; Kiziltas, A.; Mohanty, A. Recycled poly (lactic acid)-based 3D printed sustainable biocomposites: A comparative study with injection molding. Mater. Today Sustain. 2020, 7, 100027.

20. Burgos, N.; Armentano, I.; Fortunati, E.; Dominici, F.; Luzi, F.; Fiori, S.; Cristofaro, F.; Visai, L.; Jimenez, A.; Kenny, J.M. Functional Properties of Plasticized Bio-Based Poly(Lactic Acid)_Poly(Hydroxybutyrate) (PLA_PHB) Films for Active Food Packaging. Food Bioprocess Technol. 2017, 10, 770-780. [CrossRef]

21. da Silva, T.F.; Menezes, F.; Montagna, L.S.; Lemes, A.P.; Passador, F.R. Preparation and characterization of antistatic packaging for electronic components based on poly(lactic acid)/carbon black composites. J. Appl. Polym. Sci. 2019, 136. [CrossRef]

22. Wang, M.; Wu, Y.; Li, Y.D.; Zeng, J.B. Progress in Toughening Poly(Lactic Acid) with Renewable Polymers. Polym. Rev. 2017, 57, 557-593. [CrossRef]

23. Tsouknidas, A.; Pantazopoulos, M.; Katsoulis, I.; Fasnakis, D.; Maropoulos, S.; Michailidis, N. Impact absorption capacity of 3D-printed components fabricated by fused deposition modelling. Mater. Des. 2016, 102, 41-44. [CrossRef]

24. Darie-Nita, R.N.; Vasile, C.; Irimia, A.; Lipsa, R.; Rapa, M. Evaluation of some eco-friendly plasticizers for PLA films processing. J. Appl. Polym. Sci. 2016, 133. [CrossRef]

25. Burgos, N.; Martino, V.P.; Jimenez, A. Characterization and ageing study of poly(lactic acid) films plasticized with oligomeric lactic acid. Polym. Degrad. Stab. 2013, 98, 651-658. [CrossRef]

26. Rapa, M.; Nita, R.N.D.; Vasile, C. Influence of Plasticizers over Some Physico-chemical Properties of PLA. Mater. Plast. 2017, 54, 73-78.

27. Maiza, M.; Benaniba, M.T.; Quintard, G.; Massardier-Nageotte, V. Biobased additive plasticizing Polylactic acid (PLA). PolimerosCienc. E Tecnol. 2015, 25, 581-590. [CrossRef]

28. Yang, X.; Xu, H.; Odelius, K.; Hakkarainen, M. Poly(lactide)-g-poly(butylene succinate-co-adipate) with High Crystallization Capacity and Migration Resistance. Materials 2016, 9, 313. [CrossRef]

29. Garcia, D.; Balart, R.; Sanchez, L.; Lopez, J. Compatibility of recycled PVC/ABS blends. Effect of previous degradation. Polym. Eng. Sci. 2007, 47, 789-796. [CrossRef]

30. Juarez, D.; Ferrand, S.; Fenollar, O.; Fombuena, V.; Balart, R. Improvement of thermal inertia of styrene-ethylene/butylene-styrene (SEBS) polymers by addition of microencapsulated phase change materials (PCMs). Eur. Polym. J. 2011, 47, 153-161. [CrossRef]

31. Garcia-Garcia, D.; Crespo-Amoros, J.E.; Parres, F.; Samper, M.D. Influence of Ultraviolet Radiation Exposure Time on StyreneEthylene-Butadiene-Styrene (SEBS) Copolymer. Polymers 2020, 12, 862. [CrossRef]

32. Zhang, Z.X.; Dai, X.R.; Zou, L.; Wen, S.B.; Sinha, T.K.; Li, H. A developed, eco-friendly, and flexible thermoplastic elastomeric foam from SEBS for footwear application. Express Polym. Lett. 2019, 13, 948-958. [CrossRef]

33. Parameswaranpillai, J.; Joseph, G.; Shinu, K.; Jose, S.; Salim, N.V.; Hameed, N. Development of hybrid composites for automotive applications: Effect of addition of SEBS on the morphology, mechanical, viscoelastic, crystallization and thermal degradation properties of PP/PS-x GnP composites. RSC Adv. 2015, 5, 25634-25641.

34. Parameswaranpillai, J.; Jose, S.; Siengchin, S.; Hameed, N. Phase morphology, mechanical, dynamic mechanical, crystallization, and thermal degradation properties of PP and PP/PS blends modified with SEBS elastomer. Int. J. Plast. Technol. 2017, 21, 79-95. [CrossRef]

35. Parameswaranpillai, J.; Joseph, G.; Shinu, K.P.; Sreejesh, P.R.; Jose, S.; Salim, N.V.; Hameed, N. The role of SEBS in tailoring the interface between the polymer matrix and exfoliated graphene nanoplatelets in hybrid composites. Mater. Chem. Phys. 2015, 163, 182-189. [CrossRef]

36. De Carvalho, A.P.A.; Sirqueira, A.D. Effect of compatibilization in situ on PA/SEBS blends. Polimeros-Cienc. E Tecnol. 2016, 26, 123-128. [CrossRef]

37. Finotti, P.F.; Costa, L.C.; Capote, T.S.; Scarel-Caminaga, R.M.; Chinelatto, M.A. Immiscible poly (lactic acid)/poly (E-caprolactone) for temporary implants: Compatibility and cytotoxicity. J. Mech. Behav. Biomed. Mater. 2017, 68, 155-162. [CrossRef]

38. Garcia-Garcia, D.; Ferri, J.; Boronat, T.; López-Martínez, J.; Balart, R. Processing and characterization of binary poly (hydroxybutyrate)(PHB) and poly (caprolactone)(PCL) blends with improved impact properties. Polym. Bull. 2016, 73, 3333-3350. [CrossRef]

39. Mhlabeni, T.; Pillai, S.K.; Ray, S.S. Effect of organically modified layered double hydroxides on the properties of poly(lactic acid)/poly (butylene succinate)-co-adipate immiscible blends. J. Appl. Polym. Sci. 2020, 137. [CrossRef]

40. Wang, W.Q.; Ying, J.; Wang, J.K. The reactive compatibilization effect of copolymer macroactivator for immiscible anionic polyamide 6/polystyrene blends via in situ polymerization. J. Appl. Polym. Sci. 2018, 135. [CrossRef]

41. Aguilar-Bolados, H.; Quijada, R.; Yazdani-Pedram, M.; Maldonado-Magnere, S.; Verdejo, R.; Lopez-Manchado, M.A. SEBSGrafted Itaconic Acid as Compatibilizer for Elastomer Nanocomposites Based on BaTiO3 Particles. Polymers 2020, $12,643$. [CrossRef] [PubMed]

42. Zhan, Z.M.; He, H.Z.; Zhu, Z.W.; Xue, B.; Wang, G.Z.; Chen, M.; Xiong, C.T. Blends of rABS and SEBS: Influence of In-Situ Compatibilization on the Mechanical Properties. Materials 2019, 12, 2352. [CrossRef] [PubMed] 
43. Mengual, A.; Juarez, D.; Balart, R.; Ferrandiz, S. PE-g-MA, PP-g-MA and SEBS-g-MA compatibilizers used in material blends. Procedia Manuf. 2017, 13, 321-326. [CrossRef]

44. Torres-Giner, S.; Montanes, N.; Boronat, T.; Quiles-Carrillo, L.; Balart, R. Melt grafting of sepiolite nanoclay onto poly (3hydroxybutyrate-co-4-hydroxybutyrate) by reactive extrusion with multi-functional epoxy-based styrene-acrylic oligomer. Eur. Polym. J. 2016, 84, 693-707. [CrossRef]

45. Raquez, J.M.; Degee, P.; Nabar, Y.; Narayan, R.; Dubois, P. Biodegradable materials by reactive extrusion: From catalyzed polymerization to functionalization and blend compatibilization. Comptes Rendus Chim. 2006, 9, 1370-1379. [CrossRef]

46. Quiles-Carrillo, L.; Duart, S.; Montanes, N.; Torres-Giner, S.; Balart, R. Enhancement of the mechanical and thermal properties of injection-molded polylactide parts by the addition of acrylated epoxidized soybean oil. Mater. Des. 2018, 140, 54-63. [CrossRef]

47. Fombuena, V.; Sánchez-Nácher, L.; Samper, M.; Juarez, D.; Balart, R. Study of the properties of thermoset materials derived from epoxidized soybean oil and protein fillers. J. Am. Oil Chem. Soc. 2013, 90, 449-457. [CrossRef]

48. Balart, J.; Fombuena, V.; Fenollar, O.; Boronat, T.; Sánchez-Nacher, L. Processing and characterization of high environmental efficiency composites based on PLA and hazelnut shell flour (HSF) with biobased plasticizers derived from epoxidized linseed oil (ELO). Compos. Part B Eng. 2016, 86, 168-177.

49. Garcia-Garcia, D.; Ferri, J.M.; Montanes, N.; Lopez-Martinez, J.; Balart, R. Plasticization effects of epoxidized vegetable oils on mechanical properties of poly (3-hydroxybutyrate). Polym. Int. 2016, 65, 1157-1164. [CrossRef]

50. Sarwono, A.; Man, Z.; Bustam, M.A. Blending of epoxidised palm oil with epoxy resin: The effect on morphology, thermal and mechanical properties. J. Polym. Environ. 2012, 20, 540-549.

51. Liminana, P.; Quiles-Carrillo, L.; Boronat, T.; Balart, R.; Montanes, N. The Effect of Varying Almond Shell Flour (ASF) Loading in Composites with Poly (Butylene Succinate (PBS) Matrix Compatibilized with Maleinized Linseed Oil (MLO). Materials 2018, 11, 2179. [CrossRef]

52. Quiles-Carrillo, L.; Montanes, N.; Sammon, C.; Balart, R.; Torres-Giner, S. Compatibilization of highly sustainable polylactide/almond shell flour composites by reactive extrusion with maleinized linseed oil. Ind. Crop. Prod. 2018, 111, 878-888. [CrossRef]

53. Farah, S.; Anderson, D.G.; Langer, R. Physical and mechanical properties of PLA, and their functions in widespread applicationsA comprehensive review. Adv. Drug Deliv. Rev. 2016, 107, 367-392. [CrossRef]

54. Lima, J.C.C.; Araujo, E.A.G.; Agrawal, P.; Melo, T.J.A. PLA/SEBS Bioblends: Influence of SEBS Content and of Thermal Treatment on the Impact Strength and Morphology. Macromol. Symp. 2019, 383. [CrossRef]

55. Nehra, R.; Maiti, S.N.; Jacob, J. Analytical interpretations of static and dynamic mechanical properties of thermoplastic elastomer toughened PLA blends. J. Appl. Polym. Sci. 2018, 135. [CrossRef]

56. Tjong, S.C.; Xu, S.A.; Li, R.K.Y.; Mai, Y.W. Mechanical behavior and fracture toughness evaluation of maleic anhydride compatibilized short glass fiber/SEBS/polypropylene hybrid composites. Compos. Sci. Technol. 2002, 62, 831-840. [CrossRef]

57. Ferri, J.M.; Garcia-Garcia, D.; Sanchez-Nacher, L.; Fenollar, O.; Balart, R. The effect of maleinized linseed oil (MLO) on mechanical performance of poly(lactic acid)-thermoplastic starch (PLA-TPS) blends. Carbohydr. Polym. 2016, 147, 60-68. [CrossRef]

58. Kaczmarek, H.; Nowicki, M.; Vuković-Kwiatkowska, I.; Nowakowska, S. Crosslinked blends of poly (lactic acid) and polyacrylates: AFM, DSC and XRD studies. J. Polym. Res. 2013, 20, 91. [CrossRef]

59. Luyt, A.S.; Kelnar, I. Effect of blend ratio and nanofiller localization on the thermal degradation of graphite nanoplatelets-modified PLA/PCL. J. Therm. Anal. Calorim. 2019, 136, 2373-2382. [CrossRef]

60. Chow, W.S.; Tham, W.L.; Poh, B.T.; Ishak, Z.A.M. Mechanical and Thermal Oxidation Behavior of Poly(Lactic Acid)/Halloysite Nanotube Nanocomposites Containing N,N'-Ethylenebis(Stearamide) and SEBS-g-MA. J. Polym. Environ. 2018, 26, $2973-2982$. [CrossRef]

61. Yu, X.; Wang, X.; Zhang, Z.; Peng, S.; Chen, H.; Zhao, X. High-performance fully bio-based poly (lactic acid)/polyamide11 (PLA/PA11) blends by reactive blending with multi-functionalized epoxy. Polym. Test. 2019, 78, 105980. [CrossRef]

62. Silverajah, V.; Ibrahim, N.A.; Yunus, W.M.Z.W.; Hassan, H.A.; Woei, C.B. A comparative study on the mechanical, thermal and morphological characterization of poly (lactic acid)/epoxidized palm oil blend. Int. J. Mol. Sci. 2012, 13, 5878-5898. [CrossRef]

63. Lascano, D.; Moraga, G.; Ivorra-Martinez, J.; Rojas-Lema, S.; Torres-Giner, S.; Balart, R.; Boronat, T.; Quiles-Carrillo, L. Development of injection-molded polylactide pieces with high toughness by the addition of lactic acid oligomer and characterization of their shape memory behavior. Polymers 2019, 11, 2099. [CrossRef]

64. Guo, Q.; Li, X.; Li, W.; Yao, Z. The balanced insulating performance and mechanical property of PP by introducing PP-g-PS graft copolymer and SEBS elastomer. Ind. Eng. Chem. Res. 2018, 57, 6696-6704. [CrossRef]

65. Qiu, Z.; Yang, W. Crystallization kinetics and morphology of poly (butylene succinate)/poly (vinyl phenol) blend. Polymer 2006, 47, 6429-6437. [CrossRef]

66. Quiles-Carrillo, L.; Montanes, N.; Jorda-Vilaplana, A.; Balart, R.; Torres-Giner, S. A comparative study on the effect of different reactive compatibilizers on injection-molded pieces of bio-based high-density polyethylene/polylactide blends. J. Appl. Polym. Sci. 2019, 136, 47396. [CrossRef]

67. Harris, A.M.; Lee, E.C. Improving mechanical performance of injection molded PLA by controlling crystallinity. J. Appl. Polym. Sci. 2008, 107, 2246-2255. [CrossRef] 
68. Quiles-Carrillo, L.; Fenollar, O.; Balart, R.; Torres-Giner, S.; Rallini, M.; Dominici, F.; Torre, L. A comparative study on the reactive compatibilization of melt-processed polyamide 1010/polylactide blends by multi-functionalized additives derived from linseed oil and petroleum. eXPRESS Polym. Lett. 2020, 14, 586-604. [CrossRef]

69. Gonçalves, L.M.G.; Rigolin, T.R.; Frenhe, B.M.; Bettini, S.H.P. On the Recycling of a Biodegradable Polymer: Multiple Extrusion of Poly (Lactic Acid). Mater. Res. 2020, 23. [CrossRef]

70. Ge, F.; Ding, Y.; Yang, L.; Huang, Y.; Jiang, L.; Dan, Y. Effect of the content and distribution of ultraviolet absorbing groups on the UV protection and degradation of polylactide films. RSC Adv. 2015, 5, 70473-70481. [CrossRef]

71. Luna, C.B.B.; Gomes, F.B.C.; Ferreira, E.D.S.B.; Araújo, E.M.; Ferreira, R.D.S.B.; Wellen, R.M.R. Photo-degradation of PS/SBRr blends compatibilized with SEBS. Mater. Res. Express 2019, 6, 095327. [CrossRef]

72. Vogler, E.A. Structure and reactivity of water at biomaterial surfaces. Adv. Colloid Interface Sci. 1998, 74, 69-117. [CrossRef]

73. Fang, Q.; Ye, F.; Yang, X. Influence of hydrolysis of polyvinyl alcohol on its lubrication for styrene-ethylene-butylene-styrene block copolymer. Tribol. Int. 2019, 134, 408-416. [CrossRef] 